\title{
FREQUENCY DISTRIBUTION OF SPECTRUM OF CLINICAL PRESENTATIONS IN HYPOTHYROIDISM OF BOTH CLINICAL AND SUBCLINICAL CASES IN SRM MEDICAL COLLEGE HOSPITAL AND RESEARCH CENTRE
}

\author{
Nandakumar Ramachandran ${ }^{1}$, Vibisha Pragash ${ }^{2}$
}

${ }^{1}$ Assistant Professor, Department of General Medicine, SRM Medical College Hospital and Research Centre, Kattankulathur, Tamilnadu, India.

${ }^{2}$ CRRI, Department of General Medicine, SRM Medical College Hospital and Research Centre, Kattankulathur, Tamilnadu, India.

\section{ABSTRACT}

\section{BACKGROUND}

In the recent years, there has been a rapid increase in the number of patients getting diagnosed with clinical and subclinical hypothyroidism. We conducted a study to determine the current prevalence of this rising problem, and to identify rare clinical features for which patients seek medical help and get diagnosed as clinical or subclinical hypothyroidism.

\section{METHODS}

This study is a cross sectional study. The study was done over a period of 2 months (May and June 2018) on patients who visited the medicine and endocrine OPDs in SRM Medical College and Hospital, Kattankulathur. Seventy-six patients, who were proved to have either clinical or subclinical hypothyroidism and were satisfying all criteria were screened for different symptoms \& signs of hypothyroidism with the help of a questionnaire.

\section{RESULTS}

On analysing the obtained data, it was observed that some of the features deemed as rare were in fact encountered in significant proportions of the population. $76.32 \%$ of the cases were women and the remainder were men. The overall ratio of clinical to subclinical cases was found to be 1.7:1. Overall, ages 14-24 had the maximum number of cases and ages 65+ had the minimum number of cases. Overall, most common symptom was found to be obesity, and the least common was found to be carpel tunnel syndrome. A more detailed explanation is given in the discussions part of this article.

\section{CONCLUSIONS}

$76.32 \%$ of the cases were women and the remainder were men. The overall ratio of clinical to subclinical cases was found to be 1.7 : 1. Ages 45-54 had the maximum number of cases in the male population, and ages 14 to 24 had the maximum number of cases in female population. Among men, the most common symptom was found to be fatigue and least common symptom was carpel tunnel syndrome. In females the most common symptom was found to be weight gain and the least common was found to be carpel tunnel syndrome. A more detailed explanation is given in Results and Discussions part of this article.

HOW TO CITE THIS ARTICLE: Ramachandran N, Pragash V. Frequency distribution of spectrum of clinical presentations in hypothyroidism of both clinical and subclinical cases in SRM medical college hospital and research centre. J. Evolution Med. Dent. Sci. 2019;8(21):1686-1689, DOI: $10.14260 /$ jemds/2019/371

\section{BACKGROUND}

Overt hypothyroidism refers to a condition where there is decrease in levels of circulating thyroid hormones (Serum T4) and an increase in Thyroid stimulating hormone levels, whereas subclinical hypothyroidism refers to a condition where there is increase in thyroid stimulating hormone levels with normal levels of circulating thyroid hormones.(1) However for this statement to stand correct there must be an intact hypothalamic-pituitary-thyroid axis with absence of concurrent illness, and reproducibility of this trend over at least a 4-week period according to Almandoz JP, et al.(2) The prevalence of thyroid dysfunction has become a common entity nowadays.

'Financial or Other Competing Interest': None.

Submission 27-04-2019, Peer Review 15-05-2019,

Acceptance 17-05-2019, Published 27-05-2019.

Corresponding Author:

Nandakumar Ramachandran,

Flat 1A, Bristol Courts Apartment,

No. A39, Alagesan Nagar

Chengalpattu-603001,

Tamilnadu, India.

E-mail: nandy.ramachandran@gmail.com

DOI: $10.14260 /$ jemds/2019/371

\section{(c) (i) $(2)$}

According to Calsolaro $\mathrm{V}$, et al "The high frequency of hypothyroidism among the general population in Western Countries made levothyroxine (LT4) one of the 10 most prescribed drugs.'(3) Individuals from all age groups and both sexes, irrespective of young or old can be affected, especially in elderly individuals the clinical features may be atypical, and the diagnosis easily missed(4) and studies have shown that as much as $4.8 \%$ of elderly can have thyroid disorders. ${ }^{(5)}$ Yet this disease has not been fully understood i.e. the connection between the classical hypothyroid symptoms \& biochemical thyroid function has not yet been fully elicited. A wide range of clinical symptoms including all the systems of the body starting from Central nervous system, the Gastrointestinal system to even the skin can get affected by hypothyroidism.(6) Furthermore subclinical hypothyroidism raises a controversy regarding the approach to its treatment \& management and nearly $2-5 \%$ of subclinical cases of hypothyroidism annually can progress to overt hypothyroidism.(7) A better understanding of these concepts can open new scopes for research studies aiming at better modalities of treatment. Thereby estimating the frequency distribution of the various signs and symptoms with respect to age, sex etc. can prove to be a guide to direct future studies along to the right track. 


\begin{tabular}{|c|c|c|}
\hline & Male No. (\%) & Female No. (\%) \\
\hline Number of Cases & $18(23.68)$ & $58(76.32)$ \\
\hline \multicolumn{2}{|c|}{ Table 1. Sex Wise Distribution of Cases } \\
\hline
\end{tabular}

\begin{tabular}{|c|c|c|c|c|c|}
\hline 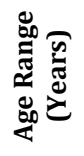 & 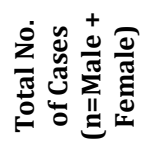 & 离 & 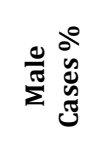 & 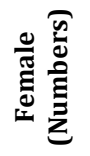 & 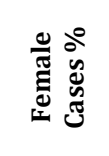 \\
\hline $14-24$ & 20 & 2 & $11.11 \%$ & 18 & $31.03 \%$ \\
\hline $25-34$ & 15 & 3 & $16.66 \%$ & 12 & $20.68 \%$ \\
\hline $35-44$ & 12 & 3 & $16.66 \%$ & 9 & $15.51 \%$ \\
\hline $45-54$ & 16 & 5 & $27.77 \%$ & 11 & $18.96 \%$ \\
\hline $55-64$ & 8 & 2 & $11.11 \%$ & 6 & $10.34 \%$ \\
\hline $65+$ & 5 & 3 & $16.66 \%$ & 2 & $3.44 \%$ \\
\hline \multicolumn{6}{|c|}{ Table 2. Age Wise Distribution of Cases } \\
\hline
\end{tabular}

\begin{tabular}{|c|c|c|c|c|c|}
\hline & 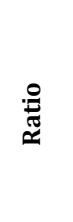 & 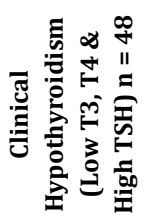 & 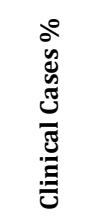 & 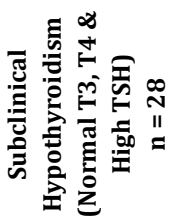 & 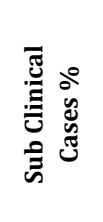 \\
\hline Male & $2: 1$ & 12 & $66.67 \%$ & 6 & $33.3 \%$ \\
\hline Female & $1.6: 1$ & 36 & $62.07 \%$ & 22 & $37.93 \%$ \\
\hline & & $63.15 \%$ & & $36.84 \%$ & \\
\hline
\end{tabular}

\begin{tabular}{|c|c|c|c|c|c|c|c|c|}
\hline $\begin{array}{c}\text { Presenting } \\
\text { Complaints } \\
\text { /Clinical } \\
\text { Features }\end{array}$ & $\begin{array}{c}\text { Total } \\
\text { No. of } \\
\text { Case } \\
\text { (n) }\end{array}$ & $\mathbf{1 4 - 2 4}$ & $\mathbf{2 5 - 3 4}$ & $\mathbf{3 5 - 4 4}$ & $\mathbf{4 5 - 5 4}$ & $\mathbf{5 5 - 6 4}$ & $>\mathbf{6 5}$ & $\%$ \\
\hline Obesity & 8 & 2 & 2 & 1 & 3 & 0 & 0 & 44.4 \\
\hline Fatigue & 12 & 1 & 2 & 2 & 3 & 2 & 2 & 66.7 \\
\hline Infertility & 4 & 0 & 3 & 1 & 0 & 0 & 0 & 22.2 \\
\hline Snoring & 5 & 0 & 2 & 0 & 3 & 0 & 0 & 27.8 \\
\hline $\begin{array}{c}\text { Bowel } \\
\text { disturbance }\end{array}$ & 12 & 1 & 2 & 3 & 2 & 2 & 2 & 66.7 \\
\hline $\begin{array}{c}\text { Cold } \\
\text { intolerance }\end{array}$ & 6 & 1 & 2 & 1 & 1 & 0 & 1 & 33.3 \\
\hline Skin changes & 6 & 0 & 1 & 2 & 3 & 0 & 0 & 33.3 \\
\hline Ataxia & 2 & 0 & 0 & 1 & 1 & 0 & 0 & 11.1 \\
\hline Dysphagia & 1 & 0 & 0 & 0 & 1 & 0 & 0 & 5.6 \\
\hline $\begin{array}{c}\text { Carpel Tunnel } \\
\text { Syndrome }\end{array}$ & 0 & 0 & 0 & 0 & 0 & 0 & 0 & 0 \\
\hline Alopecia & 3 & 0 & 2 & 1 & 0 & 0 & 0 & 16.7 \\
\hline No symptoms & 2 & 0 & 0 & 0 & 1 & 0 & 1 & 11.1 \\
\hline \multicolumn{7}{|c|}{ Table 4. Age Wise Distribution of Symptoms (Male) } \\
\hline
\end{tabular}

\begin{tabular}{|c|c|c|c|c|c|c|c|c|}
\hline \multirow{2}{*}{$\begin{array}{c}\text { Presenting } \\
\text { Complaints } \\
\text { /Clinical } \\
\text { Features }\end{array}$} & \multirow{2}{*}{$\begin{array}{l}\text { Total } \\
\text { No. of } \\
\text { Cases } \\
\text { (n) } \\
\end{array}$} & \multicolumn{6}{|c|}{ Age Groups (Years ) } & \multirow[b]{2}{*}{$\%$} \\
\hline & & $14-24$ & $25-34$ & $35-44$ & $45-54$ & 55-64 & $>65$ & \\
\hline Obesity & 35 & 9 & 6 & 8 & 8 & 4 & 0 & 60.3 \\
\hline Fatigue & 26 & 4 & 7 & 3 & 5 & 6 & 1 & 44.8 \\
\hline Infertility & 9 & 2 & 5 & 2 & 0 & 0 & 0 & 15.5 \\
\hline Snoring & 22 & 4 & 5 & 4 & 6 & 2 & 1 & 37.9 \\
\hline $\begin{array}{c}\text { Bowel } \\
\text { disturbance } \\
\end{array}$ & 20 & 6 & 4 & 3 & 3 & 2 & 2 & 34.5 \\
\hline $\begin{array}{c}\text { Cold } \\
\text { intolerance } \\
\end{array}$ & 9 & 2 & 3 & 0 & 4 & 0 & 0 & 15.5 \\
\hline $\begin{array}{c}\text { Menstrual } \\
\text { disturbance }\end{array}$ & 25 & 10 & 8 & 4 & 2 & 1 & 0 & 43.1 \\
\hline Skin changes & 15 & 3 & 3 & 1 & 5 & 1 & 2 & 25.9 \\
\hline Ataxia & 5 & 0 & 1 & 0 & 2 & 1 & 1 & 8.6 \\
\hline Dysphagia & 3 & 0 & 0 & 1 & 2 & 0 & 0 & 5.2 \\
\hline $\begin{array}{c}\text { Carpel Tunnel } \\
\text { Syndrome }\end{array}$ & 2 & 0 & 1 & 0 & 0 & 1 & 0 & 3.4 \\
\hline Alopecia & 29 & 12 & 8 & 5 & 2 & 2 & 0 & 50 \\
\hline No symptoms & 14 & 4 & 2 & 3 & 5 & 0 & 0 & 24.1 \\
\hline
\end{tabular}

Table 5. Age Wise Distribution of Symptoms (Female)
This can be achieved through an observational study, wherein individual patients can be targeted and questioned regarding the symptoms they faced at the time of diagnosis and finally combining the data obtained and plotting the obtained information in the in the form of a graphs.

\section{Aims and Objectives}

The objective is to determine the frequency distribution of the various clinical presentations of individuals coming with both clinical \& subclinical hypothyroidism and ultimately observe for any pattern in the presentations and record the data in the form of a graph and to observe for any age or sex wise favourability of signs and symptoms.

\section{METHODS}

This study is a cross sectional study which was conducted on patients visiting the Endocrinology \& Medical OPDs' of SRM Medical College Hospital and Research Centre. Our sample size is 76 patients, selected by simple random sampling. Patients were asked to fill a questionnaire regarding the symptoms that caused them to seek medical help and the signs observed by the physician during the time of diagnosis were also noted.

The questionnaire included details regarding the age at which they were diagnosed, the clinical symptoms experienced by the patient and the signs observed by the doctor, blood levels of Thyroid hormones at the time of diagnosis.

\section{Signs and Symptoms That Were Included}

- Skin: Dry skin, dry hair, swelling around eyes (Periorbital oedema), purple lips, malar flush, regions of reticulated oedema, alopecia, cold intolerance, etc.(8)

- GIT: Constipation, weight gain, colicky pain (Ileus) and abdominal swelling (Ascites).

- $\quad$ RS: Pleural effusion

- CVS: Pericardial effusion, bradycardia and hypertension

- Nervous System: carpel tunnel syndrome (Dry scaly skin, brittle nails, ape deformity, etc), cerebellar ataxia(impaired coordination, i.e., trouble performing day to day activities like eating with hands, unsteady gait, uncontrolled eye movements, etc), psychosis(myxedema madness), depression and delayed relaxation of reflexes. ${ }^{(9)}$

- Muscles: muscle stiffness(Myotonia)

- Other Symptoms: fatigue, somnolence, hoarseness of voice, impotence, infertility and menorrhagia (Menstrual disturbances), galactorrhoea, etc.

Of these a few symptoms like menorrhagia are exclusively in females whereas the other signs and symptoms can occur in either sex. The blood levels of free-T3, free-T4 and thyroid stimulating hormone (TSH) at the time of the diagnosis were collected. The target population included all adult patients $>14$ years diagnosed within the span of 2 years \& excluding those who were diagnosed before 2 years so that exact details can be obtained, keeping in mind that beyond 2 years memory lapse can lead to subjective errors. The study was done over a period of 2 months (May-June 2018) on patients who visited the medicine and endocrine OPDs. Based on previous year data during the months of May and June there were about 50 cases fitting the criteria and we are 
anticipating the same number however if more or less than anticipated number turn up, it will be accepted. Descriptive statistics such as frequency and percentage were used to describe the data obtained. The signs and symptom definitions are according to the standard definitions in Davidson's Principles and Practice of Medicine 22nd edition. The criteria for selection of patients includes:

\section{Inclusion Criteria}

1. Known cases of hypothyroidism \& subclinical hypothyroidism both males and females.

2. Newly diagnosed cases.

3. Cases diagnosed within 2 years.

4. Patients $>14$ years of age.

\section{Exclusion Criteria}

1. Thyroid dysfunction in pregnancy.

2. Patients diagnosed more than 2 years before.

3. Patients less than 14 yrs. of age.

\section{Statistical Analysis}

The data obtained were analysed and represented in tables, depicting the number and percentages of occurrence of symptoms. Clinical features were compared age wise, sex wise to look for predominance of clinical features of hypothyroidism.

\section{RESULTS}

On analysing the obtained data, it was observed that some of the features deemed as rare were in fact encountered in significant proportions of the population. $76.32 \%$ of the cases were women and the remainder were men. The overall ratio of clinical: subclinical cases was found to be 1.7: 1. Overall ages 14-24 had the maximum number of cases and ages 65+ had the minimum number of cases. Overall most common symptom was found to be obesity and the least common was found to be carpel tunnel syndrome. A more detailed explanation is given in Discussions part of this article.

\section{DISCUSSION}

The data obtained was tabulated and analysed. The following are the findings. It was observed that some of the features deemed as rare were in fact encountered in significant proportions of the population,(1.2) for example, symptoms such as ataxia and dysphagia which are not usually mentioned in the medical textbooks were also reported in a significant number of cases.

The proportion of clinical hypothyroidism was found to be $63.15 \%$ and the remaining subclinical cases were $36.84 \%$. The ratio of clinical: subclinical cases among males and females was found to be 2:1 and 1.6:1 respectively with an overall ratio of $1.7: 1$. Breaking this further down $66.67 \%$ of the male population had clinical hypothyroidism and $33.3 \%$ of the males were subclinical. Contradicting this pattern in women clinical cases were only $62.07 \%$ and subclinical cases were found to be $37.93 \%$. Thereby this data shows that clinical cases were more among males than females compared to the subclinical cases where female cases were more. According to Usha Mennon V et al 4\% of the south Indian population have clinical and $9 \%$ have subclinical hypothyroidism.(10) It is well known that with increasing number of people being screened more and more subclinical cases are being identified and this trend has raised a popular debate regarding its treatment, where some advice early initiation of treatment and others deny it. Many studies have shown that treatment with substitution therapy should be initiated in subclinical patients because these patients are at an increased risk of developing various other health related problems such as dyslipidaemia, CV events, neuromuscular disorders, and occurrence of general symptoms at later stages of their lives. Although there isn't enough evidence that levothyroxine therapy could lower the values of total and LDL cholesterol, it's beneficial effects cannot be ignored. Physicians are advised to decide on a case-by-case basis, and are also advised to consider other factors, for example, if the patient is a smokers or has any other risk factors such as cardiovascular disease (Hypertension, insulin resistance and diabetes, renal failure, etc.) and so on.(11) The most common negative consequence of levothyroxine therapy faced when treating subclinical cases are the risk of them developing subclinical hyperthyroidism or as in some cases iatrogenic hyperthyroidism for which, the patients have to be monitored with TSH values periodically to avoid this. Between $10 \%$ and $33 \%$ of patients who take levothyroxine have values of TSH below normal, and in more than half of these patients, TSH is less than $0.1 \mathrm{mU} / \mathrm{L}^{(11)}$ Another question which arises is regarding the effects of levothyroxine on the bones and heart. However, studies that have examined the effects of TSH suppression by levothyroxine replacement on bone density did not give definitive conclusions regarding the topic of early initiation of therapy lead to an increased risk of osteoporosis. As for the effects on the heart, subclinical hyperthyroidism in people older than 60 years is associated with increased 10 year risk of developing atrial fibrillation.(12) All these facts highlight the importance of the disease. This research is an attempt to bring to light the pattern of disease presentation between male and female population regarding which much details are not available, in the hope that this information opens up more opportunities for further research.

In contrast to previous studies where male: female ratio of $1: 10,(13)$ via this study we obtained a ratio of $1: 3$ male: female, that is, $76.32 \%$ of the reported cases were women, refer to table 1. Many more studies should be done in future to see this change in trend. Among women $31.03 \%$ belonged to the ages 14 to 24 . The least age distribution among reported females was ages $65+$ constituting $3.45 \%$, refer to table 2. This is unique to the scenario observed in males where ages $45-54$ had the maximum number of cases constituting $27.78 \%$ (refer to table 2). On the overall maximum cases were observed in ages 14-24 with 20 among the 76 cases and minimum cases were found among the ages $65+$ constituting 5 among the 76 cases. Among the $23.68 \%$ of reported male cases, (Refer to table 4 ), $60.34 \%$ of the women had complained of obesity and 50\% had problems regarding hair loss. Carpel tunnel syndrome was more among the female population constituting $3.45 \%$, refer to table 5 compared to $0 \%$ of the male population and on the overall carpel tunnel syndrome was found to be the least common. Whereas symptoms such as ataxia was found to be more common in the male population constituting $11.11 \%$ (Table 4) compared to the female population of $8.62 \%$ (Refer to Table 5). Obesity on the overall was found to be the most common symptom proving the information found in almost all textbooks. 
A unique trend observed in this study was that as age increases the number of cases complaining of alopecia had a decreasing tendency. This pattern was more pronounced among the female population (Refer Table 5). Another intriguing observation made is that maximum range of symptoms was observed among ages 25 to 34 . This holds true for both sexes (Tables 4,5). Menstrual disturbances were observed in $43.1 \%$ of the female population. Symptoms such as fatigue, bowel disturbances, infertility, cold intolerance, were more common among male population (Table 4) and symptoms such as skin changes were more in female population (Table 5). Dysphagia was found to have a similar percentage in both populations. Overall $24.1 \%$ of female population and $11.1 \%$ of the male population were asymptomatic and had sought medical services for other reasons.

\section{CONCLUSIONS}

Among 76 cases, $76.32 \%$ of the cases were women and the remaining $23.68 \%$ were men. The overall ratio of clinical hypothyroidism: subclinical hypothyroidism cases was found to be 1.7: 1 . Ages 45-54 had the maximum number of cases in the male population and ages 14 to 24 had the maximum number of cases in female population. Among men the most common symptom was found to be fatigue and least common symptom was carpel tunnel syndrome. In females the most common symptom was found to be weight gain and the least common was found to be carpel tunnel syndrome.

\section{REFERENCES}

[1] Walker BR, Colledge NR, Ralston SH, et al. Davidson's Principles and Practice of medicine. 22nd edn. Churchill Livingstone 2014: p. 741, 743 (hypothyroidism), 745 (subclinical hypothyroidism).

[2] Almandoz JP, Gharib H. Hypothyroidism: etiology, diagnosis and management. Med Clin North Am 2012;96(2):203-21.

[3] Calsolaro V, Niccolai F, Pasqualetti G, et al. Overt and subclinical hypothyroidism in the elderly: When to treat? Front Endocrinol (Lausanne) 2019;10:177.
[4] Hallengren B. Hypothyroidism -- clinical findings, diagnosis, therapy. Thyroid tests should be performed on broad indications. Lakartidningen 1998;95(38):4091-6.

[5] Szabolcs I, Ploenes C, Bernard W, et al. Screening of geriatric patients for thyroid dysfunction with thyrotropin-releasing-hormone test, sensitive thyrotropin and free thyroxine estimation. Horm Metab Res 1990;22(5):298-302.

[6] Canaris GJ, Manowitz NR, Mayor G, et al. The Colorado thyroid disease prevalence study. Arch Intern Med 2000;160(4):526-34.

[7] Khandelwal D, Tandon N. Overt and subclinical hypothyroidism: Who to treat and how? Drugs 2012;72(1):17-33.

[8] Keen MA, Hassan I, Bhat MH. A clinical study of the cutaneous manifestations of hypothyroidism in Kashmir valley. Indian J Dermatol 2013;58(4):326.

[9] Biondi B, Cooper DS. The clinical significance of subclinical thyroid dysfunction. Endocr Rev 2008;29(1):76-131.

[10] Usha MV, Sundaram KR, Unnikrishnan AG, et al. High prevalence of undetected thyroid disorders in an iodine sufficient adult south Indian population. J Indian Med Assoc 2009;107(2):72-7.

[11] Chu JW, Crapo LM. The treatment of subclinical hypothyroidism is seldom necessary. J Clin Endocrinol Metab 2001;86(10):4591-9.

[12] Sawin CT, Geller A, Wolf PA, et al. Low serum thyrotropin concentrations as a risk factor for atrial fibrillation in older persons. $\mathrm{N}$ Engl J Med 1994;331(19):1249-52.

[13] Okosieme 0, Gilbert J, Abraham P, et al. Management of primary hypothyroidism: statement by the British Thyroid Association Executive Committee. Clinc Endocrinol (Oxf) 2016;84(6):799-808. 